\title{
Semptomsuz Hipertansiyon Hastalarında Fragmente QRS ve Karotis İntima-Media Kalınlığı Arasındaki İlişsi
}

\section{Relationship Between Fragmented QRS and Carotid İntima-Media Thickness in Symptom Free Patients with Hypertension}

\author{
Zeydin Acar $^{1,2^{*}}$, Murat Ziyrek ${ }^{3}$ \\ ${ }^{1}$ Avrasya Üniversitesi Sağlık Bilimleri Fakültesi, Trabzon, Türkiye \\ ${ }^{2}$ Kardiyoloji Kliniği, Medicalpark Karadeniz Hastanesi, Trabzon, Türkiye \\ ${ }^{3}$ Kardiyoloji Kliniği, Sağlık Bilimleri Üniversitesi, Konya Eğitim ve Araştırma Hastanesi, Türkiye \\ email: drzeydin@yahoo.com, muziyrek@yahoo.com \\ Orcid:0000-0002-0288-7499 \\ Orcid:0000-0003-4032-7561 \\ *Sorumlu yazar/Corresponding author: Zeydin Acar ${ }^{1}$
}

Gönderim tarihi/Received:25.02.2020

Kabul tarihi/Accepted:08.04.2020

DOI: $10.34087 /$ cbusbed.693837

\section{$\ddot{\mathbf{O} z}$}

Giriş ve Amaç: Karotis intima-media kalınlığı (KIMK), hipertansiyon kaynaklı uç organ hasarının bir göstergesi olmasına rağmen klinik pratikte kullanımı kısıtlıdır. Fragmente QRS (fQRS) EKG de dal bloğu yokluğunda QRS çentiklenmesi varlığıdır. Hipertansif hastalarda sol ventrikül hipertrofisi ve fibrozisi nedeniyle bozulmuş elektriksel homojenite fQRS gelişimine yol açar. Bu çalışmada, fQRS ile KIMK ilişkisinin değerlendirilmesi ve böylece fQRS'in artmış KIMK ile saptanan hipertansif uç organ hasarının bir göstergesi olarak kullanılıp kullanılmayacağı araştırıldı.

Gereç ve Yöntemler: Çalışma populasyonu EKG'de fQRS olan (90 hasta) ve olmayan (90 hasta) yaş ve cinsiyet uyumlu semptomsuz hipertansiyon hastalarından oluşturuldu. fQRS varlığı rutin poliklinik değerlendirmesinde elde edilen oniki derivasyonlu EKG ile değerlendirildi. Tüm hastaların rutin ekokardiyografik değerlendirmesi (sol ventrikül ve sol atriyum çapları, ejeksiyon fraksiyonu, duvar kalınlıkları) ve KIMK ölçümü yapıldı. $>0.9$ mm değerler artmış KIMK olarak kabul edildi. Artmış KIMK'nın bağımsız belirleyicilerini bulmak için çok değişkenli lojistik regresyon analizi yapıldı.

Bulgular: fQRS olan ve olmayan hastalar arasında demografik özellikler ve temel ekokardiyografik özellikler açısından anlamlı farklılık yoktu. KIMK, fQRS olan hastalarda olmayanlardan anlamlı olarak daha fazlaydı $(0.95 \pm 0.20$ 'e karşılık $0.76 \pm 0.13, \mathrm{p}<0.001)$. Çok değişkenli analizde fQRS varlığ 1 artmış KIMK ile bağımsız olarak ilişkili bulundu.

Sonuçlar: Semptomsuz hipertansif hastalarda EKG'de fQRS varlığı artmış KIMK ile bağımsız olarak ilişkilidir. Bu hastaların rutin klinik takibinde fQRS saptanması uç organ hasarını gösterebilir. Çalışma sonuçlarımızın teyidi için ileri araştırmalara ihtiyaç vardır.

Anahtar Kelimeler: Fragmente QRS, hipertansiyon, karotis intima-media kalınlığ

\footnotetext{
Abstract

Objective: Carotid intima-media thickness (CIMT) is an indicator of hypertension induced end-organ damage, but its use is limited in clinical practice. Fragmented QRS (fQRS) is the presence of notching in QRS without bundle branch block. Impaired electrical homogeneity caused by hypertension induced left ventricular hypertrophy and fibrosis causes the development of fQRS. In this study, it was aimed to assess the relationship between fQRS and CIMT so that to investigate whether fQRS can be used as an indicator for hypertension induced end-organ damage detected by increased CIMT.

Materials and Methods: Study population was consisted of age and gender matched symptom free hypertensive patients with fQRS (90 patients) and without fQRS (90 patients). The presence of fQRS was assessed by 12 derivation ECG. Routine echocardiographic assessment (left ventricle and atrium diameters, ejection fraction, wall thicknesses) and the measurement of CIMT were made for all patients. The value of $>0.9 \mathrm{~mm}$ was accepted as
} 
increased CIMT. The multivariable logistic regression analysis was used to find independent predictors of increased CIMT.

Results: There were no statistical differences between patients with and without fQRS for demographic fetaures and baseline echocardiographic features. CIMT was higher in patients with fQRS than those wirthout fQRS $(0.95 \pm 0.20$ vs $0.76 \pm 0.13, \mathrm{p}<0.001)$. In multivariable analysis, the presence of fQRS was independently associated with increased CIMT.

Conclusion: The presence of fQRS in symptom free hypertensive patients is independently associated with increased CIMT. The detection of fQRS during routine clinical follow-up of these patients may suggest end-organ damage. Further studies are need to confirm our results

Key words: Carotid intima-media thickness, hypertension, fragmented QRS,

\section{Giriş}

Kalp ve damar damar sistemi hipertansiyona bağlı uç organ hasarında etkilenen temel doku ve organlardandır. Karotis intima media kalınlığı (KIMK), ana karotis arterin iç iki tabakasının kalınlığıdır. Artmış KIMK, hipertansiyona bağlı atardamar uç organ hasarının bir göstergesi olarak kabul edilmektedir [1]. Fragmente QRS (fQRS), elektrokardiyografide dal bloğu yokluğunda QRS kompleksinde çentiklenme olmasıdır [2]. Sol ventrikül myokardında fibrozis varlığında homojen olmayan elektriksel aktivite nedeniyle görülür. Kontrolsüz hipertansiyon vasküler sistemde KIMK artışına ve kalpte sol ventrikülde hipertrofi ve fibrozise yol açar [3,4]. Bu nedenle, hipertansiyon hastalarında uç organ hasarına ait belirgin semptomlar olmasa bile fragmente QRS gelişimi beklenebilir.

Uç organ hasarı gelişiminin önlenmesi ve erken tespiti hipertansiyon yönetiminde sakat kalma ve ölüm oranlarını azaltan temel yaklaşımlardan biridir [1]. KIMK, hipertansiyona bağlı uç organ hasarının saptanmasında kullanılan güvenilir bir yöntemdir. Bununla birlikte, KIMK ölçümü ultrasonografik bir yöntem olup klinik pratikteki rutin hasta takibinde zaman kaybı ve ekonomik maliyete yol açmaktadır. Bu nedenle, hipertansif hastaların klinik rutin takibinde olası uç organ hasarını semptomsuz evrede saptayabilecek basit, ucuz ve güvenilir yöntemlere ihtiyaç vardır. Bu çalışmada, belirgin klinik semptomu olmayan hipertansiyon hastalarında, sol ventrikül hasarının bir göstergesi olan fQRS ile vasküler hasarın bir göstergesi olan artmış KIMK arasındaki olası ilişkinin varlığı araştırıldı. Bu sayede, EKG ile basitçe değerlendirilebilecek fQRS varlığının olası uç organ hasarını öngörmedeki değeri incelendi.

\section{Materyal ve Metod}

\subsection{Hasta seçimi}

Çalışmaya kardiyoloji polikliniğine başvuran ve uç organ hasarına bağlı belirgin klinik şikayeti olmayan hipertansiyon hastaları alındı. Dışlama kriterleri olarak; EKG de dal bloğu varlığı, koroner arter hastalığı (myokard infarktüsü, perkütan koroner girişim, koroner by-pass veya stabil angina pektoris), serebrovasküler hastalık (iskemik veya hemorajik inme), böbrek fonksiyon bozukluğu (artmış kreatinin veya proteinüri) veya ritm bozukluğu (atriyal fibrilasyon, ventriküler taşikardi, ventriküler ekstrasistol) varlığı belirlendi. değerlendirildi. Artmış KIMK'nın bağımsız prediktörleri multivariable lojistik regresyon analizi ile
EKG de fQRS olan hastalar (grup 1), fQRS olmayan yaş ve cinsiyet uyumlu hastalarla eşleştirildi (grup 2). Dışlama kriterleri olamayan hastalar yazılı onayları alındıktan sonra çalışmaya dahil edildi.

\subsection{Fragmente $Q R S$}

fQRS varlığı rutin kontrol esnasında elde edilen 12 derivasyonlu EKG ile değerlendirildi. Bir major koroner arter alanına uyan ardışı iki derivasyonda eşlik eden dal bloğu olmaksızın RSR' paterni varlığı (RSR', RSr RSR', rSR RSR' veya rSr RSR') fragmente QRS olarak kabul edildi [5].

2.3. Ekokardiyografik değerlendirme ve Karotis intimamedia kalınlığ ölçümü

Ekokardiyografik ölçümler, sol lateral dekübitis pozisyonunda parasternal uzun aks, parasternal kısa aks, apikal iki ve dört boşluk görüntüleme kullanılarak yapıldı. Tüm ölçümler Vivid S5 ekokardiyografi cihazı 3S-RS ve 9L-RS problar1 (GE Health-care, USA) kullanılarak yapıldı. Parasternal uzun aks görüntülemede sol ventrikül sistolik ve diyastolik çapları, sol atriyum çap1, septum ve arka duvar kalınlıkları ölçüldü. Ejeksiyon fraksiyonu sistolik ve diyastolik çap kullanılarak Teichholz metodu ile hesapland1.

KIMK, sağ ortak karotis arterden aynı cihazda lineer (vasküler) prop kullanılarak ile ölçüldü. Hasta supin pozisyonda yatarken karotis bifurkasyona yaklaşı $1 \mathrm{~cm}$ mesafeden ana karotis arterin iç iki tabakasının kalınlığı ölçüldü. $1 \mathrm{~mm}$ aralıklarla ardışık 5 ölçüm yapıldı ve ortalaması kullanıldı. Ölçümler milimetre olarak ifade edildi. Belirgin karotis darlığ 1 veya lokalize plağ hastalar dişlandı. İntima-media kalınlığ $1>0.9 \mathrm{~mm}$ olması, artmış KIMK olarak kabul edildi [6]. Tüm ölçümler 2 farklı kişi tarafından yapıldı (ZA, MZ). Tekrarlanabilirlik ve değişkenlik hesaplanması için on hastanın ölçümleri 2 farklı günde tekrarlandı ve BlandAltman metoduyla değerlendirildi [7]. Kişiler arası değişkenlik \%4 ve ölçümler arası değişkenlik \%3,9 olarak hesaplandi.

2.4. Istatiksel analiz

Kategorik değişkenler yüzde değer, sürekli değişkenler ortalama \pm standart sapma olarak ifade edildi. Kategorik değişkenler Chi-square testi ile karşılaştırıldı. Sürekli değişkenlerin normal dağılıma uygunluğu Kolmogorov Smirnov testi ve histogram ile değerlendirildi. Normal dağılıma uyan değişkenler student t-test ile normal dağılıma uymayanlar ise Mann Whitney-U testi ile 
belirlendi. Tüm istatiksel analiz SPSS 20.0 programı kullanılarak yapıldı (SPSS Inc, Chigago, IL). P<0.05 değeri istatiksel olarak anlamlı kabul edildi.

\section{Bulgular}

Tablo 1. Çalıșma populasyonunun demografik özellikleri ve ekokardiyografik verilerin karşılaștırılması

\begin{tabular}{|c|c|c|c|}
\hline & $\begin{array}{l}\text { fQRS (+) } \\
(\mathrm{n}=90)\end{array}$ & $\begin{array}{l}\text { fQRS }(-) \\
(n=90)\end{array}$ & $\mathbf{P}$ \\
\hline Yaş, yıl (ortalama \pm SS) & $58.4 \pm 8.3$ & $57.6 \pm 9.4$ & 0.65 \\
\hline Cinsiyet (erkek), n (\%) & $46(51.1 \%)$ & $44(48.9 \%)$ & 0.89 \\
\hline RAS bloker, n (\%) & $70(77.8 \%)$ & $57(63.3 \%)$ & 0.05 \\
\hline Kalsiyum antagonist, $n(\%)$ & $27(30 \%)$ & $27(30 \%)$ & 1.0 \\
\hline Beta bloker, n (\%) & $23(25.6 \%)$ & $32(35.6 \%)$ & 0.2 \\
\hline Diabetes mellitus, n (\%) & $16(18.0 \%)$ & $13(14.4 \%)$ & 0.55 \\
\hline Sigara, $\mathrm{n}(\%)$ & $13(14.6 \%)$ & $10(11.1 \%)$ & 0.51 \\
\hline Artmış CIMT & $42(46.7 \%)$ & $8(8.9 \%)$ & $<0.001$ \\
\hline EF & $64.4 \pm 2.9$ & $64.1 \pm 2.9$ & 0.61 \\
\hline SVSSÇ & $28.5 \pm 4.1$ & $28.4 \pm 3.7$ & 0.79 \\
\hline SVDSÇ & $43.4 \pm 4.4$ & $44.0 \pm 3.4$ & 0.45 \\
\hline IVS & $12.3 \pm 3.2$ & $11.8 \pm 1.3$ & 0.26 \\
\hline AD & $10.7 \pm 1.7$ & $10.5 \pm 1.2$ & 0.20 \\
\hline SA & $34.9 \pm 3.4$ & $34.8 \pm .3 .3$ & 0.65 \\
\hline KIMK & $0.95 \pm 0.20$ & $0.76 \pm 0.13$ & $<0.001$ \\
\hline
\end{tabular}

Artmıș CIMT: >0.9 mm, RAS: Renin angiotensin aldosterone sistemi, SS: Standart sapma, AD : Sol ventrkül arka duvar kalınlığı, EF: Ejeksiyon fraksiyonu, IVS: İnterventriküler septum kalınlığı, KIMK: Karotis intima-media kalınlığı, SA: Sol atriyum çapı, SVDSÇ: Sol ventrikül diyastol sonu çapı, SVSSÇ : Sol ventrikül sistol sonu çapı,

KIMK ve artmıș KIMK prevelansı ise fQRS grubunda anlamlı olarak daha fazlaydı (Tablo 1). Lojistik regresyon analizinde; fQRS $(\mathrm{OR}=9.54, \mathrm{p}<0.001)$, Beta bloker $(\mathrm{OR}=4.25, \mathrm{p}=0.007)$, yaş $(\mathrm{OR}=1.06, \mathrm{p}=0.01)$ ve sol ventrikül arka duvar kalınlığ $\mathrm{p}=0.02$ ) uç organ hasarının belirteci olan, artmış KIMK ığ 1 ile bağımsız ilişkili bulundu (Tablo 2).

\section{Tartışma}

$\mathrm{Bu}$ çalışmada, uç organ hasarına bağlı belirgin klinik şikayeti olmayan hipertansiyon hastalarında fQRS'in, artmış KIMK varlığıyla değerlendirilen uç organ hasarıyla ilişkisi araştırıldı. Bu popülasyonda fQRS varlığı, hipertansiyon kaynaklı uç organ hasarı ile
Çalışmaya fQRS olan (grup 1) 90 ve fQRS olmayan (grup 2) 90 kişi olmak üzere toplam 180 semptomsuz hipertansif hasta dahil edildi. Her iki grubun temel demografik özellikleri ve ekokardiyografik ölçümleri arasında anlamlı istatiksel farklılık saptanmadı (Tablo $1)$. 
Tablo 2. KIMK ve diğer değişkenler arasında tek değiş̧kenli ve çok değişkenli analiz sonuçları

\begin{tabular}{|l|c|c|c|c|c|c|c|c|}
\hline & \multicolumn{4}{|c|}{ Tek değişkenli analiz } & \multicolumn{4}{c|}{ Çok değişkenli analiz } \\
\hline \multirow{2}{*}{} & \multirow{2}{*}{ OR } & \multicolumn{2}{|c|}{$95 \% \mathrm{CI}$} & \multirow{2}{*}{$\mathrm{p}$} & \multirow{2}{*}{ OR } & \multicolumn{2}{|c|}{$95 \% \mathrm{CI}$} & \multirow{2}{*}{$\mathrm{p}$} \\
\cline { 3 - 4 } & & lower & upper & & & lower & upper & \\
\hline Yaş & 1.05 & 1.01 & 1.09 & 0.01 & 1.06 & 0.02 & 1.12 & 0.01 \\
\hline fQRS & 8.69 & 3.89 & 20.69 & $<0.001$ & 9.54 & 3.89 & 23.53 & $<0.001$ \\
\hline RAS bloker & 2.78 & 1.20 & 6.43 & 0.017 & 1.72 & 0.64 & 4.58 & 0.28 \\
\hline Beta bloker & 3.6 & 1.50 & 8.62 & 0.004 & 4.25 & 1.49 & 12.14 & 0.007 \\
\hline AD & 1.43 & 1.11 & 1.84 & 0.005 & 1.42 & 1.05 & 1.92 & 0.02 \\
\hline
\end{tabular}

AD: Sol ventrikül arka duvar kalınlığı, fQRS: Fragmente QRS, KIMK: Karotis intima-media kalınlığı, fQRS: Fragmente QRS, RAS: Renin angiotensin-aldosteron sistemi

Bununla birlikte, KIMK ölçümünün ultrasonografik bir yöntem olması hem ilave zamana hem de ek maliyete yol açmaktadır. Bu nedenlerle, KIMK ölçümü her ne kadar güvenilir bir yöntem olsa da rutin hasta takibinde kullanımı kısıtlıdır. Bu nedenle, gündelik rutin pratikte uç organ hasarını gösterebilecek basit, güvenilir ve maliyeti düşük yöntemlere ihtiyaç vardır. fQRS, son iki dekatta tanımlanan ve kullanımı yaygınlaşan bir EKG bulgusudur. Dal bloğu yokluğunda $\operatorname{ard}$ şık 2 derivasyonda QRS kompleksinde çentiklenme olmasını ifade eder [5]. Normal bir kalpte elektriksel uyarı, iletim sistemi sayesinde tüm myokardda homojen olarak gerçekleşir. Myokardiyal fibrozis varlığında elektrik iletiminde homojenite bozulur ve heterojen elektriksel aktivasyon EKG de fQRS gelişmesine yol açar. Bu nedenle; myokardiyal fibrozisin geliştiği iskemi, myokard infarktüsü ve hipertrofisi gibi yapısal myokardiyal bozulma durumlarında fQRS görülebilmektedir. $\mathrm{Bu}$ çalışmada, semptomsuz hipertansif hastaların rutin klinik takibinde s1klıkla değerlendirilen 12 derivasyonlu EKG'de kolaylıkla saptanabilen fQRS varlığının artmış KIMK ile bağımsız ilişkili olduğunu gösterdik. Çalışma sonucumuzun klinik rutin hasta takibinde önemli etkisi olması beklenebilir. Hipertansif hastaların rutin takibinde kan basinc1 düzeyinin tesbiti ve temel biyokimyasal tetkiklerin yanısıra oniki derivasyonlu EKG'de sıklıkla elde edilmektedir. EKG, bu popülasyonda, her ne kadar, temel olarak ritim, iskemi ve hipertrofik değişiklikler açısından incelense de fQRS varlığı gibi artmış KIMK yansitmaz. Ayrica, bu hastalarda olması muhtemel sol ventrikül hipertrofisi de EKG'nin iskemik açıdan değerlendirmesinde zorluğa yol açabilmektedir. fQRS ise böylesi bir kısıtlılığa sahip değildir. Üstelik, KIMK, bu popülasyondaki uç organ hasarını yansıtmanın yanısıra iyi bilinen bir subklinik ateroskleroz göstergesidir [9]. Bu nedenle, fQRS varlığının yansıttığ artmış KIMK, bu popülasyonda hem uç organ hasarını hemde ateroskleroz varlığını yansıtır. Böylece, fQRS olan hastalarda hem yaşam tarzı değişikliği hemde medikal tedavinin daha yoğun ve efektif kullanılması sakat kalma ve ölüm riskin de rutin klinik takibe göre ilave katkı sağlayabilir.

Çalışmamızda bazı kısıtlılıklar mevcuttur. En önemli kısıtlılığımız göreceli olarak az hasta sayısı varlığıdır. Bununla birlikte, her iki çalışma grubu temel demografik özellikler açısından eşleştirilerek bunun çalışma sonuçlarımıza etkisi azaltılmaya çalışıldı. Diğer bir kısıtlılığımızda, çalışma popülasyonunun hastalık süresini ve ilaç kullanımını dikkate almadan oluşturulmasıdır. Sadece yeni tanı hipertansif hastalardan oluşan bir popülasyonda mevcut bulguların varlığı hipertansiyon teşhis aşamasında ve ilaç etkisiden arındırılmış olarak yüksek riskli hastaları yansıtacağından klinik tedavi seçimi ve başlangıç araştırmasının planlanmasında ilave faydalar sağlayabilirdi. Bununla birlikte, hem regresyon analizinin kullanılması hemde hastaların ilaç kullanım verisinin istatiksel analize dahil edilmesi ile bu kısıtlılığın etkisi azaltılmaya çalışıldı.

\section{Sonuç}

Aşikar klinik semptomu olmayan hipertansif hastalarda, oniki derivasyonlu EKG'de fQRS güvenilir bir uç organ hasarı belirteci olan artmış KIMK ile bağımsız olarak ilişkilidir. Bu hasta grubunda, fQRS varlığı hipertansif uç organ hasarını yansıtabilir.

\section{Referanslar}

1.2018 ESC/ESH Guidelines for the management of arterial hypertension, European Heart Journal, 2018, 39, 3021-3104.

2. Das, MK, Khan, B, Jacob, S, Kumar, A, Mahenthiran, J, Significance of a fragmented QRS complex versus a $\mathrm{Q}$ wave in patients with coronary artery disease, Circulation, 2006, 113, 2495501

3.Havranek, EP, Emsermann, CD, Froshaug, DN, Masoudi, FA, Krantz, MJ, Hanratty, $\mathrm{R}$ et al, Thresholds in the relationship between mortality and left ventricular hypertrophy defined by electrocardiography, Journal of Electrocardiology, 2008, 41, 342350.

4. Rosen, BD, Edvardsen, T, Lai, S, Castillo, E, Panl, Jerosch-Herold $\mathrm{M}$ et al, Left ventricular concentric remodeling is associated with decreased global and regional systolic function: the Multi-Ethnic Study of Atherosclerosis, Circulation, 2005, 112, 984-91.

5. Reddy, CV, Cheriparambill, K, Saul, B, Makan, M, Kassotis, J, Kumar, A et al, Fragmented left sided QRS in absence of bundle 
branch block: sign of left ventricular aneurysm. Annals of Noninvasive Electrocardiology, 2006, 11(2), 132-8.

6. Vlachopoulos C, Xaplanteris, P, Aboyans, V, Brodmann, M, Cifkova, R, Cosentino, $\mathrm{F}$ et al, The role of vascular biomarkers for primary and secondary prevention. A position paper from the European Society of Cardiology Working Group on peripheral circulation: endorsed by the Association for Research into Arterial Structure and Physiology (ARTERY) Society. Atherosclerosis, 2015, 241, 507-532.

7. Altman, DG, Bland, JM, Measurement in medicine: the analysis of method comparison studies, Statistician, 1983, 32, 307-17.

8. Chow, CK, Teo, KK, Rangarajan, S, Islam, S, Gupta, R, Avezum, A et al, PURE Study Investigators. Prevalence, awareness, treatment, and control of hypertension in rural and urban communities in high, middle-, and low-income countries, JAMA, 2013, 310, 959-968.

9. Grobbee DE, Bots ML, Carotid artery intima-media thickness as an indicator of generalized atherosclerosis, Journal of Internal Medicine, 1994, 236, 567-573.

http://edergi.cbu.edu.tr/ojs/index.php/cbusbed isimli yazarın CBU-SBED başlıklı eseri bu Creative Commons Alıntı-Gayriticari4.0 Uluslararası Lisans1 ile lisanslanmıștır.

(c) (7) 8 